\title{
Evaluation of the Effectiveness of Surveillance Policies to Control the COVID-19 Pandemic in São Paulo, Brazil
}

\section{Lorena G Barberia ( $\square$ lorenabarberia@usp.br)}

Universidade de São Paulo https://orcid.org/0000-0001-6319-543X

\section{Natália de P. Moreira}

Universidade de Sao Paulo Campus de Sao Paulo: Universidade de Sao Paulo

\section{Brigina Kemp}

Cosems

\section{Maria Amelia de Sousa Mascena Veras}

Faculdade de Ciências Médicas da Santa Casa de São Paulo: Faculdade de Ciencias Medicas da Santa Casa de Sao Paulo

\section{Marcela Zamudio}

Universidade de Sao Paulo Campus de Sao Paulo: Universidade de Sao Paulo

\section{Isabel Seelaender Costa Rosa}

Universidade de Sao Paulo Campus de Sao Paulo: Universidade de Sao Paulo

\section{Rebeca de J. Carvalho}

Fundação Getúlio Vargas: Fundacao Getulio Vargas

\section{Tatiane M. Sousa}

Universidade de Sao Paulo Campus de Sao Paulo: Universidade de Sao Paulo

\section{Research}

Keywords: COVID-19, Surveillance, RT-PCR Public Health Testing Policies

Posted Date: November 30th, 2021

DOI: https://doi.org/10.21203/rs.3.rs-1093449/v1

License: (c) (i) This work is licensed under a Creative Commons Attribution 4.0 International License.

Read Full License 


\section{Abstract}

Background: Surveillance efforts are critical to pandemic control, especially where the state is the primary health provider, such as Brazil. When public health testing guidelines limit RT-PCRs, there are reductions in detection efforts aimed at early recognition, isolation, and treatment of those infected with the virus.

Methods: We conducted an interrupted time series analysis with a segmented regression model using publicly available data to analyze if changes in the state's guidelines improved RT-PCR testing outcomes in Brazil's most affluent and largest state, São Paulo, from March 2020 to June 2021.

Results: The São Paulo state's policy guidelines have changed substantially over time. In the first months, the public health system restricted RT-PCR testing to hospitalized cases. Testing was expanded to permit symptomatic testing of non-hospitalized persons only in July 2020. In September 2020, there was a review of the national surveillance guidelines and case definition was expanded to permit case confirmation based on clinical, laboratory and image data criteria other than an RT-PCR test. In February 2021, policies were revised to instruct public health agencies to increase epidemiological monitoring with genomic data. Results show an uneven improvement in testing outcomes following these changes across the state's regional health departments.

Conclusions: Evidence suggests that lower RT-PCR testing and genomic surveillance efforts are associated with areas characterized by a higher population concentration and a greater reliance of the population on the public health system.

\section{Key Messages}

- There was limited improvement in surveillance efforts in the State of São Paulo.

- RT-PCR testing as a surveillance strategy was not strengthened as the number of cases increased.

- The state expanded testing guidelines to include patients with respiratory infection evaluated in primary care settings in July 2020, but only after the first peak had occurred.

- In most epidemiological weeks, testing remained below the public laboratory network's processing capacity.

- In comparison to the rest of Brazil, the state of Sao Paulo made early efforts to promote genomic surveillance. However, the speed of detection is not correlated with enhanced and targeted testing to further limit VOCs spread in the state.

\section{Introduction}

Evidence from industrialized and low-resource countries has demonstrated that detection efforts to identify infected individuals are essential to an effective containment of COVID-19 along with policies aimed at movement restrictions that included border, school, and business closures, travel restrictions, 
restrictions on public gatherings, and local curfews $\left({ }^{1-4}\right)$. Molecular tests, commonly referred to as RTPCR (Reverse Transcription-Polymerase Chain Reaction) tests, are considered the gold standard as they detect the virus's RNA in infected individuals who are potentially transmitting the virus to other individuals $\left({ }^{5}\right)$. RT-PCR and rapid lateral flow (antigen) tests are considered the first-best tests for diagnosis of COVID19 and an essential part of a surveillance strategy that should include identifying and isolating infected individuals and ensuring the quarantine of close contacts. RT-PCR-positive samples are also the source used to conduct genomic surveillance, including the monitoring of variants of interest (VOI) and of concern $(\mathrm{VOC})\left({ }^{6}\right)$. However, since the onset of the pandemic, the sizable volume of resources (monetary, laboratory, test kits) and continuous surveillance policies have been identified as significant impediments to the effective use of RT-PCR tests to contain the COVID-19 pandemic in poor and middle-income countries $\left({ }^{7,8}\right)$. As the developing world struggles to contain the spread of SARS-CoV-2 and faces an increasing number of fatalities $\left({ }^{9}\right)$, enhanced understanding is needed about whether specific diagnostic interventions are improving local epidemic control efforts.

Although Brazil has less than 3 percent of the world's population and COVID-19 arrived relatively later than in Asia, Europe, and North America, the country has registered almost $10 \%$ of the world's cases (over 21 million) and nearly $13 \%$ of all deaths $(588,597)$ by July $2021\left({ }^{10}\right)$. In this study, we analyze RT-PCR public health network testing data in the first 15 months of the COVID-19 pandemic in the state of São Paulo to assess surveillance efforts. São Paulo state, the most populous state in Brazil with over 40 million inhabitants, is the epicenter of the pandemic in the country $\left({ }^{11}\right)$, and $62(\%)$ of its population depends exclusively on the public health system $\left({ }^{12}\right)$.

\section{Methods}

\section{Data}

Anonymized daily data on the RT-PCR tests conducted in the public laboratories belonging to the statewide network from March 1, 2020 to June 5, 2021 were extracted from the Sao Paulo State Health Secretariat's Intelligent Monitoring System (SIMI) $\left({ }^{13}\right)$. This open-source database provides the number of RT-PCR performed in the network of public labs for hospitalized and ambulatory patients and the overall confirmed daily case count. Data on the laboratory processing capacity of these labs were also collected from the same source. The data on the genomic sequences collected and deposited by the Instituto Adolfo Lutz network, which is responsible for sequencing the cases identified by the Center for Epidemiological Surveillance (CVE) for genomic surveillance in São Paulo state, were obtained from the Global Initiative on Sharing All Influenza Data (GISAID), which is the platform used for registering SARSCoV-2 sequences by Brazilian institutes $\left({ }^{14}\right)$. Since the objective of this study is to evaluate regional-level outcomes, the data were aggregated for the 17 regional health departments in the state.

Based on a review of official state legislation, we identified four major testing interventions that were introduced by the State of São Paulo's RT-PCR surveillance program: Testing limited to hospitalized cases 
and health professionals (Testing Policy I), which was published on March 17, 2020; Testing expanded to ambulatory symptomatic cases (Testing Policy II), which commenced on July 1, 2020; Inclusion of the clinical and epidemiological criteria as COVID-19 notification, in addition to RT-PCR testing (Testing Policy III) which was announced on September 15, 2020; and, genomic surveillance guidelines were introduced (Testing Policy IV), which were initiated on February 26, 2021. After mapping these policies, we analyzed several RT-PCR testing effort variables in the period between the publication of each policy and the publication of the following mapped policy, as the objective of the study was to analyze whether each policy positively interfered in the increase in the diagnostic testing effort. In this way, we analyzed the following periods: Testing Policy I: March 17 - June 30, 2020; Testing Policy II: July 1 - September 14, 2020; Testing Policy III: September 15, 2020 - February 25, 2021; and, Testing Policy III: February 26 - June 5 , 2021. These policies were identified through searches in the archive of the official webpage of the State of São Paulo, using the search terms "RT-PCR," "SARS-Cov-2," "test," "genomic surveillance," and "diagnosis" for the period between March 1, 2020, until June 30, 2021.

\section{Variables}

To identify variables for RT-PCR testing outcomes, we analyzed WHO, ECDC, and CDC technical guidelines and daily press conferences that specifically addressed testing $\left({ }^{15-20}\right)$, and other academic publications and platforms $\left({ }^{21-23}\right)$. Based on these documents, we identified a total of nine indicators (see Table 1). Of the nine indicators, two monitor variant surveillance as these efforts determine if emerging mutations render the virus more contagious, more potent, or resistant to existing vaccines and medicines-the remainder focus on testing outcomes and laboratory capacities at the regional level. We constructed a weekly time-series for each testing outcome indicator during each epidemiological week (SundaySaturday), the period for each of the seventeen Regional Health Departments (RHD) in the state. The RHD is the central territorial entity in which the public health system is organized in Brasil. In the State of Sao Paulo, the median number of municipalities in an RHD is 39 (minimum nine and maximum 102).

To identify if testing is associated with specific spatial and socioeconomic patterns in the public health networks across RHDs, we collected data on the 2020 population, and social vulnerability was provided from the Foundation for Statewide System Data Analysis $\left({ }^{12}\right)$. The 2010 Social Vulnerability Index of São Paulo State is based on five socioeconomic and four demographic indicators. Social vulnerability is measured as the percentage of people living in each of the 17 RHD under high or very high social vulnerability (including urban and rural areas). For each RHD, these values represent the mean value of all municipalities in the specific region. We also obtained the proportion of the population which was exclusively dependent on the Brazilian public health system, known as Sistema Único de Saúde(SUS) in Portuguese, in May 2020. The per capita income estimates are based on 2010 census data.

\section{Statistical Analysis}


We reconstructed time series data to estimate the mean change in testing indicators and 95(\%) confidence intervals (95\% Cls) for the state, and for each of the 17 RHDs between March 1, 2020 and June 5,2021 . We then conducted an interrupted time series analysis with a segmented regression model $\left({ }^{24}\right)$ to analyze if testing guidelines (Testing Policy II and III) produced changes in testing outcomes in each RHD and for the state overall. We estimated the level and trend of the reported outcome testing indicator following testing policy interventions in 2020 for the state overall and for each RHD. An interrupted time series analysis of genomic surveillance (Testing Policy IV) in 2021 was restricted to the state overall as the small sample sizes limit more robust granular statistical analyses to be undertaken for this specific outcome.

\section{Results}

The first confirmed case in Sao Paulo state was February 26, 2020. International importations accounted for a majority of cases at the outbreak's start before local cases were detected $\left({ }^{25}\right)$. Following the outbreak's spread to local community transmission, there were four major policy changes in the state's RT-PCR testing guidelines. From March 17 to June 30, 2020, state surveillance policies limited RT-PCR use to hospitalized and symptomatic individuals and health professionals. Under Testing Policy I, an average of 30 tests per 100,000 was conducted, and an average positivity rate of 25.67(\%) was observed (Table 1). When São Paulo state expanded RT-PCR testing to permit testing of non-hospitalized, symptomatic cases (Policy II), an average of 166.23 tests per 100,000 were performed, and the positivity rate of 32.21(\%) was observed from July 1, 2020 to September 14, 2020. There was a significant increase in COVID-19 cases during this period with a peak number of the average cases registered per 100,000 in weeks 32 and 33 of 2020. On September 15, 2020, the Brazilian Ministry of health expanded the notification criteria, including clinical and epidemiological criteria (Policy III). This could have resulted in an expansion of the testing effort for asymptomatic and suspicious cases. However, an average of 197.41 tests per 100, 000 between September 15, 2020 to February 252021 were registered. In this period, the average positivity rate of $31.22(\%)$ ranged from a weekly average rate of $19.76(\%)$ (week 45 , 2020) to 40.58(\%) (week one, 2021) (Figure 1, Panel a). The second highest peak in cases was observed in weeks two and four of 2021. When guidelines were revised to incorporate genomic surveillance as part of the state's RT-PCR testing strategy from February 26 to June 5, 2021 (Policy IV), an average of 305.52 tests per 100,000 were conducted, and an average positivity rate of $41.80(\%)$ was observed. This period coincides with the third highest peak in cases observed in week 22 of 2021.

Significant variation in the volume of tests conducted across the state's 17 Regional Health Departments (RHD) over the past fifteen months is observed. From March 1, 2020 to June 5, 2021, a weekly average of 168.41 RT-PCR tests per 100,000 were performed across the state. São José do Rio Preto was the RHD with the highest average of tests performed (322.07 tests per 100,000), while Grande São Paulo was the lowest average of tests conducted (74.18 tests per 100,000). There has also been a substantial variation in the positivity rate across the regions. Throughout the period, the state average positivity rate was 
$31.21(\%)$. Araraquara presented the lowest average positivity rate $(23.16 \%)$ and Registro the highest average positivity rate $(40.55 \%)$.

In the early months of the pandemic, public health testing efforts were coordinated by the Instituto Adolfo Lutz. In April 2020, a new public laboratory system was created with the Instituto Butantan as its central manager $\left({ }^{26}\right)$ to coordinate efforts to complement efforts undertaken in the IAL network. In this period, university laboratories and two private labs were incorporated into the public laboratory network to expand testing. Notwithstanding the expansion of the network and central management, public laboratories remain unequally distributed across the São Paulo state territory. Only 12 of the state's 17 Regional Health Departments (RHD) have at least one local laboratory in their region. While Grande São Paulo has four local laboratories (Instituto Adolfo Lutz Central, Instituto Adolfo Lutz Santo André, Instituto Biológico, and Instituto Butantan), five RHD do not have a local laboratory (Barretos, Franca, Registro, São João da Boa Vista, and Taubaté). There was considerable delay in expanding public health laboratory capacity in the state. Initially, RT-PCR tests were limited to processing 1,200 tests per day in the Instituto Adolfo Lutz (IAL) lab (Figure 1, Panel b). By September 2020, the public laboratory network had expanded its processing capacity to 13,154 RT-PCR tests per day. In February 2021, the state reached a capacity to process 17,394 tests per day. No further increases were observed after this date.

The state's public laboratories processing capacity is also unevenly distributed. Some laboratories have still not acquired the capacity to process tests (Instituto Adolfo Lutz Araçatuba and Instituto Adolfo Lutz Campinas). The two public laboratories with the highest daily processing capacity (Instituto Adolfo Lutz Central with a capacity of 1,100 tests and the Instituto Butantan with 4,500 tests) are in the same RHD (Grande São Paulo). The State of São Paulo also contracts private laboratories to process RT-PCR tests. These providers (DASA and Grupo Fleury) were contracted to process 1,945 tests per day in 2020. In 2021 , private laboratories were contracted to process 3,545 tests per day $(20.1 \%$ of daily testing in the network). In contrast, there was a smaller increase in the IAL network testing capacity (2,304 tests per day in September 2020 to 2,895 tests per day by February 2021). Data are only published on the date and the lab that received the RT-PCR test. The lab processing the test and the test result date are not informed in public data sources.

Between March 1, 2020, and June 5, 2021, 1,763 samples were collected for genomic sequencing from RT-PCR positive samples by the Instituto Adolfo Lutz network in the state of São Paulo $(18.06 \%$ of the 9 761 samples collected and $20.65 \%$ of the 6,324 genomes sequenced in this period in GISAID for São Paulo state). However, given delays in uploading sequences to the registry database and missing values, only 1,299 of these genomic sequences were deposited with GISAID in the same period. On average, 0.0024 of RT-PCR positive tests in each RHD in the state of São Paulo were sequenced per week. In 2020, the number of sequences registered in GISAID was limited. On average, 0.70 sequences per RHD were registered per week in 2020 (based on 0.0025 of RT-PCR positive tests). While, on average, 3.32 sequences were registered per week in 2021 (based on 0.0023 of RT-PCR positive tests). The highest weekly average was observed in week six, 2021, when 9.12 genomic sequences were performed across the RHDs. Most of the sequences were uploaded to GISAID with considerable delay. The time lag between 
the specimen collection and submission has been remarkably high in 2020 (on average, 149.3 days). Since March 2021, there has been a marked rise in sequencing and submission. The time lag has substantially decreased in 2021 (54.4 days from specimen collection to submission).

Genomic sequencing by the IAL varies considerably across the state's RHDs (Figure 2). Grande São Paulo was the RHD with the highest weekly average of genomic sequencing performed (on average, 9.54 per week), while Franca was the lowest average of genomic sequencing conducted (on average, 0.33 per week). The lag in time from collection to submissions of the SARS-CoV-2 genome to GISAID by the IAL network has also varied significantly across RHDs. In 2020, the lowest average weekly time was 97.50 days from samples in São José do Rio Preto, and the highest average was 210 days from samples collected from Baixada Santista. In 2021, this period was considerably reduced. The IAL network performed the lowest average weekly time in Registro (41 days) and the highest average in Baixada Santista (68 days). The available data do not permit verification of whether the difference in processing time is due to which laboratory of the network is performing sequencing.

For the state overall, we transformed one of these dependent variables (RT-PCR tests Positivity Rate) into first differences of their natural logarithm, which is the per-week growth rate (Table 2). The results showed a 0.005 [95(\%) confidence interval (Cl) $-0.003 ; 0.013]$ increase in the log of RT-PCR tests per $100,000,-0.0008$ [95\% confidence interval $(\mathrm{Cl})-0.0058 ; 0.0042$ ] decrease in the ratio of RT-PCR tests per case, and a $-0.0003(\%)$ [95(\%) confidence interval (Cl) $-0.0016 ; 0.001]$ decrease in the growth rate of the RT-PCR test positivity rate following Testing Policy II (Figure 3, Panel a). In turn, Testing Policy III, results showed a 0.005 [95(\%) confidence interval $(\mathrm{Cl}) 0.002 ; 0.007]$ increase in the log of RT-PCR tests per $100,000$, a 0.0076 [95(\%) confidence interval $(\mathrm{Cl})-0.0046 ; 0.0197]$ increase in the ratio of RT-PCR tests per case, and an $0.002(\%)[95(\%)$ confidence interval (Cl) $0.0004 ; 0.003(\%)]$ increase in the growth rate of the RT-PCR positivity rate. As a result, Testing Policy II did not produce a statistically significant increase in surveillance efforts. Following Testing Policy III, there was an increase in the mean volume of testing in each RHD, but the test positivity rate increased due to insufficient testing expansion.

Uneven improvements in testing outcomes were observed across the state (Figure 3, Panel b). Following Testing Policy II, an increase in the log of RT-PCR tests per 100,000 was only observed in four RHDs (RHD $\mathrm{V}, \mathrm{VIII}, \mathrm{XI}$, and $\mathrm{XVI})$ and a reduction in the log of RT-PCR tests positivity rate occurred in six RHDs $(\mathrm{X}, \mathrm{XI}, \mathrm{XII}$, $X I I I, X I V$, and XV). With respect to the ratio of RT-PCR tests per case, a decrease was observed in four RHDs (III, XIV, XV, and XVII) and an increase in five RHDs (I, II, VII, XIII, and XVI) after Testing Policy II. Under Testing Policy III, there was an increase in the log of RT-PCR tests per 100,000 in eight RHDs (I, III, $\mathrm{VI}, \mathrm{IX}, \mathrm{XI}, \mathrm{XII}, \mathrm{XIV}, \mathrm{XVI})$, and no reductions in test positivity rates were observed. Instead, test positivity rates increased after Testing Policy III in two RHDs (IX, XII). After Testing Policy III, the ratio of RT-PCR tests per case increased in two RHDs (VIII and XIII). These results are only with respect to those RHDs in which no evidence of first or second-order autocorrelation was found in the residuals after using Newey-Standard Errors for first-order serial correlation. 
The impact of genomic surveillance efforts was analyzed based on the number of samples and the time delay between sample collection and deposit to the GISAID (Table 3). Testing Policy IV did not produce a statistically significant increase in genomic surveillance efforts. Results showed a -0.020 [95(\%) confidence interval $(\mathrm{Cl})-0.046 ; 0.005]$ decrease in the number of samples and a 0.028 [95(\%) confidence interval $(\mathrm{Cl})-0.142 ; 0.198]$ increase in the time delay between sample collection and deposit to the GISAID platform after the introduction of the policy.

Considering the results related to the four analyzed policies, there is no significant association between the public RT-PCR testing variables and each policy. Figure 1 also shows that there was no improvement in the testing effort in the period studied, even though the previous policies were maintained and could have shown accumulated positive effects, with an improvement in all RT-PCR testing effort variables.

RT-PCR testing intensity and outcomes are correlated with testing policy interventions, population density, income per capita, the proportion of the population dependent on SUS and social vulnerability. RT-PCR tests per 100,000 are negatively associated with high socioeconomic vulnerability ( $p$-value $=0.000$ ) and with a higher population density ( $p$-value $=0.000)$. RT-PCR test positivity rate is positively correlated with high socioeconomic vulnerability ( $p$-value $=0.000$ ) and with a higher population density ( $p$-value $=0.013$ ), and it is negatively correlated with average income per capita ( $p$-value=0.026) (see Figure 4). COVID-19 cases, in turn, are negatively correlated with high socioeconomic vulnerability ( $p$-value $=0.027$ ) and higher population density ( $p$-value $=0.001$ ). The number of genomic sequences collected and uploaded at the GISAID is positively correlated with high socioeconomic vulnerability ( $p$-value $=0.025)$, higher population density ( $p$-value $=0.000)$, and income per capita ( $p$-value $=0.000)$, and it is negatively associated with a higher population dependent on SUS ( $p$-value $=0.000$ ). The average time delay between sample collection and deposit to the GISAID is positively correlated with high socioeconomic vulnerability ( $p$-value $=0.014)$, population density ( $p$-value $=0.000)$, and average income per capita ( $p$-value $=0.002$ ).

\section{Discussion}

When public health testing guidelines limit RT-PCRs, there are reductions in detection efforts aimed at early recognition, isolation, and treatment of those infected with SARS-CoV-2. In periods in which testing guidelines are expanded to authorize testing of a larger pool of suspected cases, we hypothesized that testing indicators would be associated with improvements in the incidence of COVID-19 infection. Findings across the state's 17 regional health departments did not support our hypotheses based on the total number of RT-PCR tests conducted per 100,000 , the test positivity rate, test processing time, proximity to local public health labs, as well as indicators to monitor surveillance efforts, including policies to conduct contact tracing, report testing outcomes based on repeated testing of individuals, and expand genomic surveillance.

There was limited improvement in surveillance efforts in the State of São Paulo. RT-PCR testing as a surveillance strategy was not strengthened as the number of cases increased. A full month after the detection of the first case in the state, guidelines were issued to restrict testing to hospitalized patients 
with pneumonia and respiratory infection in late March 2020. The state expanded testing guidelines to include patients with respiratory infection evaluated in primary care settings in July 2020, but only after the first peak had occurred. Although test positivity rates remained above recommended maximum thresholds in subsequent weeks, the testing volume expanded gradually and sporadically. In most epidemiological weeks, testing remained below the public laboratory network's processing capacity. Before the onset of the state's second and most severe wave of cases and deaths, the regulation regarding COVID-19 notification was improved in September 2020 with the inclusion of clinical and epidemiological criteria. In comparison to the rest of Brazil, the state of Sao Paulo made early efforts to promote genomic surveillance. However, although genomic sequencing increased across RHDs (see Appendix 1), the speed of detection is not correlated with enhanced and targeted testing to further limit VOCs spread in the state. The information is also being shared with a considerable delay with the global health community.

To some extent, the observed variability in surveillance reflects the heterogeneity in Brazil's most populated and well-endowed state. The Grande São Paulo region, for example, comprises 39 municipalities and has experienced high mortality rates $\left({ }^{27}\right)$. In addition, in the Greater São Paulo region, where the state capital is located, there is an enormous private health service, including private laboratories. Despite the widespread availability of public laboratories compared to the rest of the state (and other settings in Brazil), the volume of testing was relatively low compared to other regions of the state. On the other hand, some RHDs with smaller populations and public health laboratory access improved their testing efforts considerably.

Incidence is impacted by the physical distancing policies, their enforcement, and compliance $\left({ }^{11,28}\right)$. In the case of Sao Paulo, the state government coordinated the rolling implementation of various restrictions to increase distancing (starting in March 2020) across all regional health departments. When the government authorized the loosening of restrictions in June 2020, and throughout the subsequent period analyzed in this study, RT-PCR testing outcomes were not used in these assessments. Differing levels of public engagement in seeking testing across geographic settings and across times may differentially affect both individual and aggregate demand for diagnosis and reported test outcomes.

Our findings may help to explain the persistent and relatively high magnitude of cases observed in the State of Sao Paulo since the onset of the pandemic in early 2020. During the entire study period, no guidelines were identified to incorporate rapid, lateral flow antigen tests $\left({ }^{29,30}\right)$ as an additional diagnostic test to increase the capacity to identify infectious individuals and more rapidly inform them of their testing status, especially in RHDs with limited local laboratory capacity. Despite growing evidence of its effectiveness in control and containment, a contact tracing program was not introduced with specific guidelines, nor were efforts incorporated to track secondary attack rates in the state $\left({ }^{31}\right)$.

\section{Conclusion}


There is growing consensus that coordinated and unified testing and genomic surveillance systems are needed to identify, track, and mitigate the transmission of SARS-CoV-2 and the variants of concern that have spread most rapidly. In this study, we used nine indicators to measure RT-PCR testing in the 17 Regional Health Departments (RHD) of São Paulo state, the epicenter of the COVID-19 pandemic in Brazil. These indicators are based on recommendations by the World Health Organization (WHO), the European Centre for Disease Control (ECDC), and the Centers for Disease Control and Prevention (CDC). Overall, we find limited evidence that testing guidelines improved surveillance in Brazil's largest state, especially in poorer and more populous RHDs.

A major limitation of this study is that high-quality, population-based health administrative databases are not publicly accessible in the State of São Paulo. Several indicators could not be evaluated as either restricted or no information was provided in the public databases accessed by this study. Furthermore, the sample selection criteria by which positive cases are selected for sequencing are not disclosed to differentiate those cases selected based on random selection or other epidemiological criteria. Testing performed by private laboratories contracted by municipalities is not reported in the SIMI platform, nor are data on lateral flow tests conducted by municipalities in the public health system.

\section{Declarations}

\section{Contributorship Statement:}

Conception or design of the research: L.B., N.M, T.M

Data collection: M.Z., R.C, I.S.

Data analysis and interpretation: L.B., N.M, B.K., M.V., M.Z., R.C., I.S., T.M

Drafting the article: L.B., N.M, I.S., M.Z., I.S.

Critical revision of the article: B.K., M.V, T.M.

Acknowledgments: The authors acknowledge the government of the State of Sao Paulo for making the data publicly available, which made this analysis possible.

Conflicts of interest: The authors declare no conflicts of interest.

Ethical approval is not required for this research, due to the public source of data.

Consent for publication: The authors consent to publication.

Availability of data and material: The data and replication materials will be made available in the Harvard Dataverse.

Nothing to declare.: Nothing to declare. 
Funding: Nothing to declare.

\section{References}

1. Kim S, Castro MC. Spatiotemporal pattern of COVID-19 and government response in South Korea (as of May 31, 2020). International Journal of Infectious Diseases. 2020;98:328-333.

2. Summers J, Cheng $\mathrm{H}-\mathrm{Y}$, Lin $\mathrm{H}-\mathrm{H}$, et al. Potential lessons from the Taiwan and New Zealand health responses to the COVID-19 pandemic. The Lancet Regional Health-Western Pacific. 2020:100044.

3. Crozier A, Rajan S, Buchan I, McKee M. Put to the test: use of rapid testing technologies for covid-19. bmj. 2021;372

4. Pitzer VE, Chitwood M, Havumaki J, et al. The impact of changes in diagnostic testing practices on estimates of COVID-19 transmission in the United States. American Journal of Epidemiology. 2021;190(9):1908-1917.

5. Vandenberg O, Martiny D, Rochas O, van Belkum A, Kozlakidis Z. Considerations for diagnostic COVID-19 tests. Nature Reviews Microbiology. 2021;19(3):171-183.

6. Novelli G, Biancolella M, Mehrian-Shai R, et al. COVID-19 one year into the pandemic: from genetics and genomics to therapy, vaccination, and policy. Human Genomics. 2021;15(1):1-13.

7. Giri AK, Rana DR. Charting the Challenges behind the Testing of COVID-19 in Developing Countries: Nepal as a Case Study. Biosafety and Health. 2020;2(2):53-56.

8. Werneck GL, Porto LC, Sena A, et al. The incidence and geographical spread of SARS-CoV-2 in Rio de Janeiro, Brazil based on RT-PCR test results. Revista da Sociedade Brasileira de Medicina Tropical. $2021 ; 54$

9. Ranzani OT, Bastos LS, Gelli JGM, et al. Characterisation of the first 250000 hospital admissions for COVID-19 in Brazil: a retrospective analysis of nationwide data. The Lancet Respiratory Medicine. 2021;9(4):407-418.

10. Johns Hopkins University. Coronavirus Resource Center. 2021.

11. Castro MC, Kim S, Barberia L, et al. Spatiotemporal Pattern of COVID-19 Spread in Brazil. Science. 2021;372(6544):821-826.

12. Fundação Estadual Sistema Estadual de Análise de Dados (SEADE). Data from: Sistema de projeções populacionais para os municípios do estado de São Paulo. 2020.

13. Governo de São Paulo. Data from: Sistema de Monitoramento Inteligente - SIMI. 2021.

14. Global Initiative on Sharing All Influenza Data (GISAID). Data from: Genomic epidemiology of hCoV19. 2021.

15. Centers for Disease Control and Prevention (CDC). SARS-CoV-2 Testing Strategy: Considerations for Non-Healthcare Workplaces. 2020. https://www.cdc.gov/coronavirus/2019ncov/community/organizations/testing-non-healthcare-workplaces.html (Sept 13 2021, last accessed). 
16. Centers for Disease Control and Prevention (CDC). Evaluating Case Investigation and Contact Tracing Success. 2020. https://www.cdc.gov/coronavirus/2019-ncov/php/contact-tracing/contacttracing-plan/evaluating-success.html (Sept 13 2021, last accessed).

17. European Centre for Disease Prevention and Control (ECDC). Guidance for representative and targeted genomic SARS-CoV-2 monitoring. 2021. https://www.ecdc.europa.eu/en/news-events/ecdcreleases-new-dashboard-sars-cov-2-variants (Sept 13 2021, last accessed)

18. World Health Organization (WHO). Public health criteria to adjust public health and social measures in the context of COVID-19 (Version from May 12, 2020). 2020.

19. World Health Organization (WHO). Considerations for implementing and adjusting public health and social measures in the context of COVID-19 (Version 14 June 2021). 2021.

20. Pan American Health Organization (PAHO). Diretrizes laboratoriais para deteç̧ão e diagnóstico de infecção pelo vírus da COVID-19. 2020.

https://iris.paho.org/bitstream/handle/10665.2/52523/OPASIMSPHECOVID19200038_por.pdf? sequence=1\&isAllowed=y (31 August 2021, last accessed)

21. Leal FE, Mendes-Correa MC, Buss LF, et al. Clinical features and natural history of the first 2073 suspected COVID-19 cases in the Corona São Caetano primary care programme: a prospective cohort study. BMJ open. 2021;11(1):e042745.

22. Harvard Global Health Institute (HGHI). Pandemics Explained: unlocking evidence for better decision making. 2020. https://globalepidemics.org/key-metrics-for-covid-suppression/ (Sept 13 2021, last accessed)

23. Fiocruz-Instituto de Comunicação e Informação Científica e Tecnológica em Saúde (ICICT). MonitoraCovid-19. https://bigdata-covid19.icict.fiocruz.br/ (31 August 2021, last accessed)

24. Linden A. Conducting interrupted time-series analysis for single-and multiple-group comparisons. The Stata Journal. 2015;15(2):480-500.

25. Candido DS, Claro IM, De Jesus JG, et al. Evolution and epidemic spread of SARS-CoV-2 in Brazil. Science. 2020;369(6508):1255-1260.

26. Instituto Butantan. Governo de São Paulo lança plataforma de laboratórios para diagnóstico de Covid-19. 2020;

27. Ribeiro KB, Ribeiro AF, Veras MAdSM, de Castro MC. Social inequalities and COVID-19 mortality in the city of São Paulo, Brazil. International Journal of Epidemiology. 2021;

28. Barberia LG, Cantarelli LGR, Oliveira MLCdF, Moreira NdP, Rosa ISC. The Effect of State-level Social Distancing Policy Stringency on Mobility in the States of Brazil. Revista de Administração Pública. 2021;55:27-49.

29. Mina MJ, Andersen KG. COVID-19 testing: One size does not fit all. Science. 2021;371(6525):126127.

30. Mina MJ, Peto TE, García-Fiñana M, Semple MG, Buchan IE. Clarifying the evidence on SARS-CoV-2 antigen rapid tests in public health responses to COVID-19. The Lancet. 2021;397(10283):14251427. 
31. Hellewell J, Abbott S, Gimma A, et al. Feasibility of Controlling COVID-19 Outbreaks by Isolation of Cases and Contacts. The Lancet Global Health. 2020;8(4):e488-e496.

\section{Tables}

Table 1. Summary statistics São Paulo State from March 1, 2020 to June 5, $2021^{1}$

(Weekly average for all 17 RHDs and standard deviation in parenthesis) 


\begin{tabular}{|c|c|c|c|c|c|}
\hline & Overall & $\begin{array}{l}\text { Testing } \\
\text { Policy 1. } \\
\text { March 17, } \\
\text { June 30, } \\
2020 \\
\text { Testing } \\
\text { Limited to } \\
\text { Health } \\
\text { Professionals } \\
\text { and } \\
\text { Hospitalized }_{\text {Cases }^{3}}\end{array}$ & $\begin{array}{l}\text { Testing } \\
\text { Policy II. } \\
\text { July 1- } \\
\text { September } \\
\text { 14,2020 } \\
\text { (testing } \\
\text { expanded to } \\
\text { ambulatory } \\
\text { symptomatic } \\
\text { cases) }\end{array}$ & $\begin{array}{l}\text { Testing Policy III. } \\
\text { September } 15, \\
2020 \text {-February } \\
25,2021 \text { (case } \\
\text { definition } \\
\text { expanded to } \\
\text { permit case } \\
\text { confirmation } \\
\text { based on clinical, } \\
\text { laboratory and } \\
\text { image data } \\
\text { criteria other than } \\
\text { RT-PCR test) }\end{array}$ & $\begin{array}{l}\text { Testing } \\
\text { Policy IV. } \\
\text { February } \\
26,2021 \text { - } \\
\text { June 5, } \\
2021 \\
\text { (genomic } \\
\text { surveillance } \\
\text { guidelines } \\
\text { were } \\
\text { introduced) }\end{array}$ \\
\hline RT-PCR tests per & 168.41 & 29.99 & 166.23 & 197.41 & 305.52 \\
\hline $100,000^{2}$ & (134.27) & (31.18) & $(92.50)$ & (97.59) & $(123.66)$ \\
\hline Weekly COVID- & 129.95 & 29.82 & 141.86 & 126.93 & 260.69 \\
\hline 100,000 & (101.76) & (39.54) & $(60.52)$ & $(66.30)$ & (74.05) \\
\hline RT-PCR & 3.06 & 4.96 & 1.23 & 1.83 & 1.20 \\
\hline cases & (14.97) & (16.27) & $(0.54)$ & $(1.34)$ & $(0.43)$ \\
\hline RT-PCR tests & 31.21 & 25.67 & 32.21 & 31.22 & 41.79 \\
\hline & (12.38) & (12.87) & (7.69) & $(9.75)$ & $(6.83)$ \\
\hline No. of labs in $\mathrm{RH}$ & & & & & \\
\hline 0 & 5 & & & & \\
\hline$>=1$ & 12 & & & & \\
\hline $\begin{array}{l}\text { Test Processing } \\
\text { Time }\end{array}$ & No informat & on available & & & \\
\hline Weekly Total & 72445.33 & 25760 & 48363.64 & 93112.17 & 121758 \\
\hline $\begin{array}{l}\text { Processing } \\
\text { Capacity }\end{array}$ & (39317.76) & (13236.52) & (10129.08) & $(8985.50)$ & (0) \\
\hline No. of genomic & 1.56 & 1.30 & 0.37 & 1.77 & 2.68 \\
\hline $\begin{array}{l}\text { collected and } \\
\text { uploaded }\end{array}$ & $(4.49)$ & $(4.94)$ & $(1.24)$ & $(4.92)$ & $(4.92)$ \\
\hline Average lag & 89.05 & 180.28 & 157.12 & 64.16 & 55.59 \\
\hline $\begin{array}{l}\text { to submissions } \\
\text { to GISAID of } \\
\text { SARS-CoV-2 } \\
\text { genome by } \\
\text { surveillance } \\
\text { agencies (days) }\end{array}$ & $(61.20)$ & (48.35) & $(41.16)$ & (38.28) & (20.97) \\
\hline
\end{tabular}


Notes:

1. No data were identified on the number of individuals whose RT-PCR tests were repeated, nor were data identified regarding the number of contacts tracked for each positive test result, or the number of tests processed by each laboratory. For this reason, these indicators have no score assigned.

2. The data are relative to the specimens collected. There is no data available for testing encounters per individual reported by the State of São Paulo.

3. Guidelines regarding restriction of testing to hospitalized patients with pneumonia and respiratory infections were issued by the State Government through the Resolução SS - 28, de 17-3-2020, published on March 17, 2020.

4. Guidelines for expanding testing guidelines to include patients with respiratory infection evaluated in primary care settings were issued by the State Government by Deliberação CIB - 55, de 10-7-2020, on July 1, 2020.

Table 2. RT-PCR Testing in São Paulo State from March 29, 2020 to December 26, $2020^{1}$

(Weekly average for all 17 RHDs, coefficient and Newey standard errors in parenthesis) 


\begin{tabular}{|c|c|c|c|}
\hline $\begin{array}{l}\text { Dependent Variables of RT-PCR } \\
\text { Testing Outcome: }\end{array}$ & $\begin{array}{l}\text { I. Log }(R T-P C R \text { Tests per } \\
100,000)_{t}\end{array}$ & $\begin{array}{l}\text { II. RT-PCR } \\
\text { Tests/Cases }\end{array}$ & $\begin{array}{l}\text { III. Log } \\
\text { (Positivity Rate) })_{t}\end{array}$ \\
\hline \multirow[t]{2}{*}{ Intercept } & 1.95 & 8.96 & 0.04 \\
\hline & $(0.16)$ & (3.99) & $(0.09)$ \\
\hline \multirow[t]{2}{*}{ Time } & 0.02 & -0.13 & 0.00 \\
\hline & $(0.00)$ & $(0.07)$ & $(0.00)$ \\
\hline \multirow[t]{2}{*}{ Testing Policy II } & 0.71 & 4.02 & -0.09 \\
\hline & $(0.28)$ & $(2.58)$ & $(0.08)$ \\
\hline \multirow[t]{2}{*}{ Time*Post Testing Policy II } & -0.02 & 0.13 & -0.00 \\
\hline & $(0.00)$ & $(0.07)$ & $(0.00)$ \\
\hline \multirow[t]{2}{*}{ Testing Policy III } & -0.39 & 0.48 & -0.04 \\
\hline & $(0.19)$ & $(0.39)$ & $(0.05)$ \\
\hline \multirow{2}{*}{$\begin{array}{l}\text { Time*Post Testing Policy II*Post } \\
\text { Testing Policy III }\end{array}$} & -0.00 & 0.00 & 0.00 \\
\hline & $(0.00)$ & $(0.00)$ & $(0.00)$ \\
\hline \multicolumn{4}{|l|}{ Post Intervention Linear Trend: } \\
\hline Testing Policy II & 0.00 & -0.00 & -0.00 \\
\hline$(\beta 1+\beta 3)$ & $(0.00)$ & $(0.00)$ & $(0.00)$ \\
\hline Testing Policy III & 0.00 & 0.01 & 0.00 \\
\hline$(\beta 1+\beta 3+\beta 5)$ & $(0.00)$ & $(0.01)$ & $(0.00)$ \\
\hline Number of Observations & 39 & 39 & 39 \\
\hline
\end{tabular}

Notes.

1. For each dependent variable, the following segmented regression model was estimated: $Y_{t}=\beta 0+\beta 1$ time $+\beta 2$ Testing Policy II $+\beta 3$ time $e^{\star}$ post Testing Policy $\mathrm{II}_{\mathrm{t}}+\beta 4$ Testing Policy $\mathrm{III}_{\mathrm{t}}+\beta 5$ time* post Testing Policy $\mathrm{III}_{\mathrm{t}}+\varepsilon_{\mathrm{t}}$

Table 3. Genomic Surveillance in São Paulo State from December 27, 2020 to July 05, $2021^{1}$

(Weekly average for all 17 RHDs, coefficient and Newey standard errors in parenthesis) 


\begin{tabular}{|lll|}
\hline $\begin{array}{l}\text { Dependent Variables of RT-PCR } \\
\text { Testing Outcome: }\end{array}$ & $\begin{array}{l}\text { I. Number of } \\
\text { samples }\end{array}$ & $\begin{array}{l}\text { II. Time delay between sample collection and } \\
\text { deposit to the GISAID }\end{array}$ \\
\hline Intercept & 0.73 & 56.69 \\
& $(0.44)$ & $(2.48)$ \\
\hline Time & 0.14 & -0.15 \\
& $(0.03)$ & $(0.14)$ \\
\hline Testing Policy IV & -4.73 & 7.51 \\
& $(1.58)$ & $(6.79)$ \\
\hline Time*Post Testing Policy IV & -0.16 & 0.18 \\
& $(0.04)$ & $(0.17)$ \\
\hline Post Intervention Linear Trend: & & \\
\hline Testing Policy IV & -0.02 & 0.03 \\
(B1+ß3) & $(0.01)$ & $(0.08)$ \\
\hline $\begin{array}{l}\text { Number of Epidemiological } \\
\text { Weeks }\end{array}$ & 23 & 23 \\
\hline
\end{tabular}

Notes.

1. For each dependent variable, the following segmented regression model was estimated: $Y_{t}=\beta 0+\beta 1$ time $+\beta 2$ Testing Policy IV $t+\beta 3$ time*post Testing Policy $\mathrm{IV}_{\mathrm{t}}+\varepsilon_{\mathrm{t}}$

\section{Figures}

Panel a. Weekly Number of RT-PCR Tests per 100,000 (State) and Positivity Rates (for each RHD).

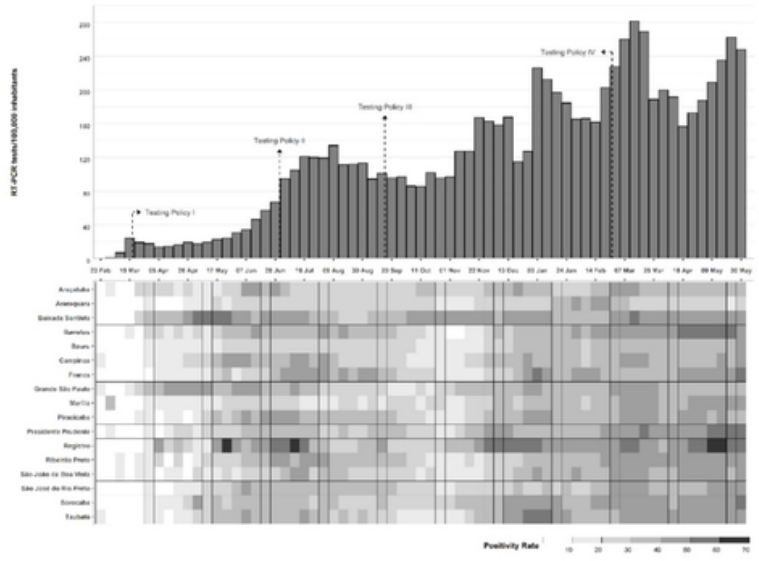

Panel b. RT-PCR Total Lab Processing Capacity and Total Processed Tests by Public Health Network Laboratories in São Paulo State

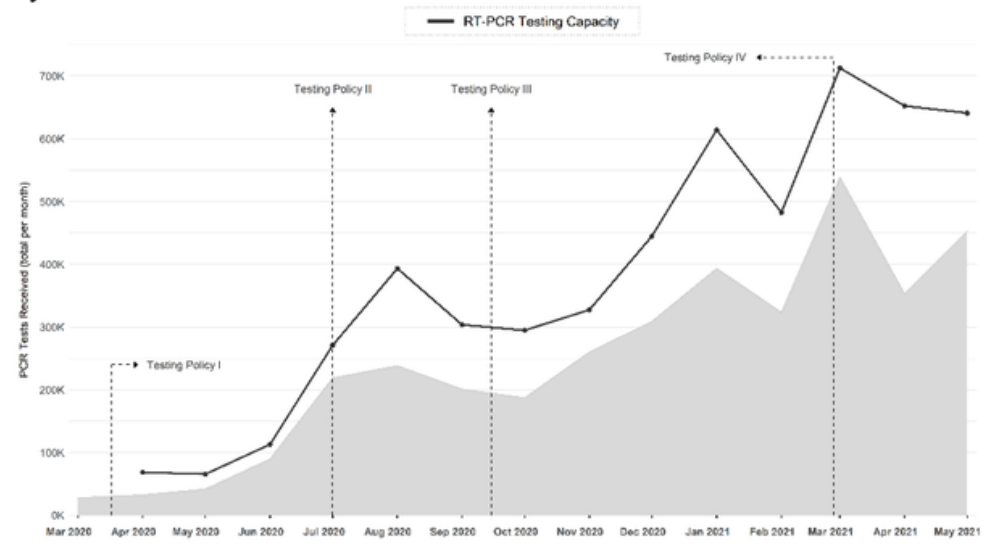


RT-PCR Tests, Test Positivity, and Laboratory Testing Capacity in the Public Health Network of São Paulo State and in each RHD (March 1, 2020 - June 5, 2021).

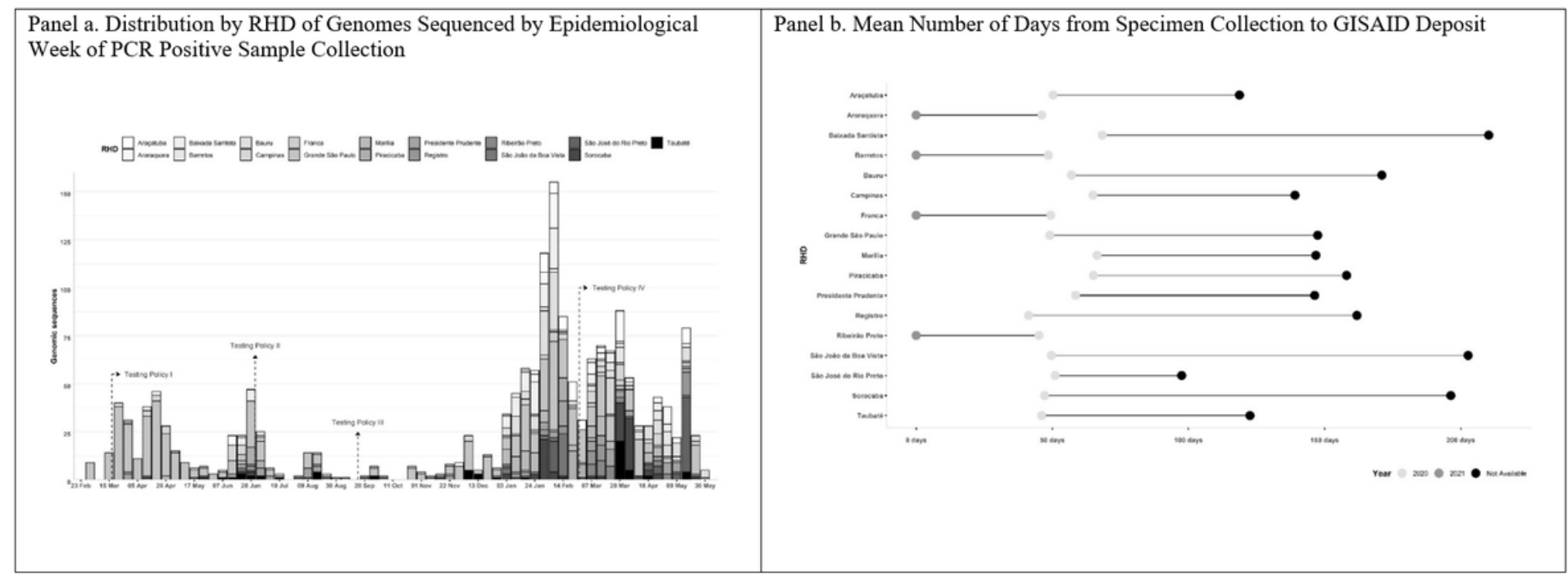

Figure 2

Genomic Sequencing in São Paulo State (March 1, 2020 -June 5, 2021) 

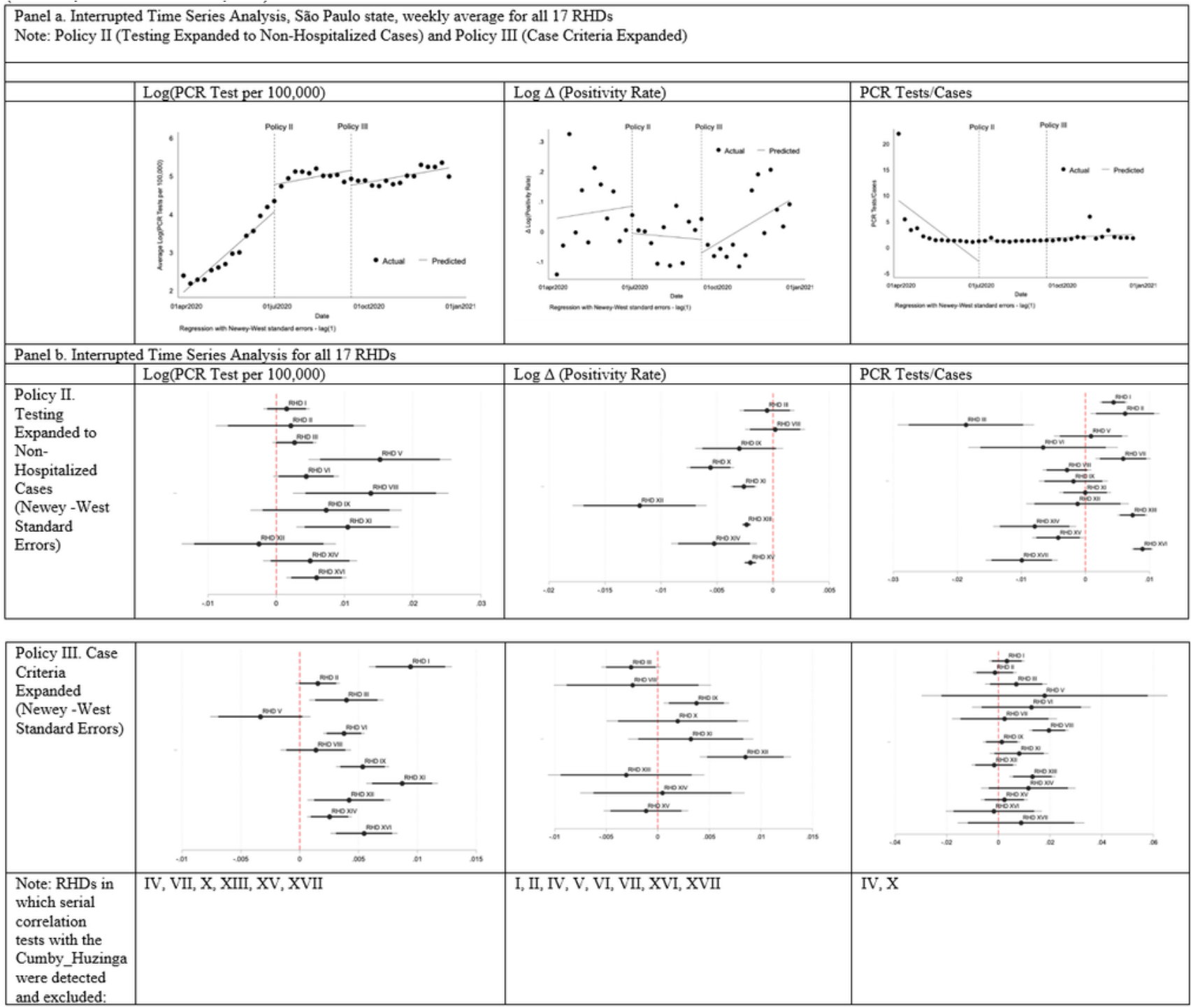

\begin{tabular}{|l|l|l|l|}
\hline $\begin{array}{l}\text { Policy III. Case } \\
\text { Criteria } \\
\text { Expanded } \\
\text { Newey -West } \\
\text { Standard Errors }\end{array}$
\end{tabular}

\section{Figure 3}

Interrupted Time Series Analysis of RT-PCR Testing in the Public Health Network of São Paulo State and in each RHD (March 29, 2020 to December 26, 2020) Note: The figure reports the coefficients and 95\% and $90 \%$ confidence interval of the post intervention linear trend estimated via interrupted time series analysis. RHD I (Grande São Paulo), II (Araçatuba), III (Araraquara), IV (Baixada Santista), V (Barretos), VI (Bauru), VII (Campinas), VIII (Franca), IX (Marília), X (Piracicaba), XI (Presidente Prudente), XII (Registro), 
XIII (Ribeirão Preto), XIV (São João da Boa Vista), XV (São José do Rio Preto), XVI (Sorocaba), and XVII (Taubaté).

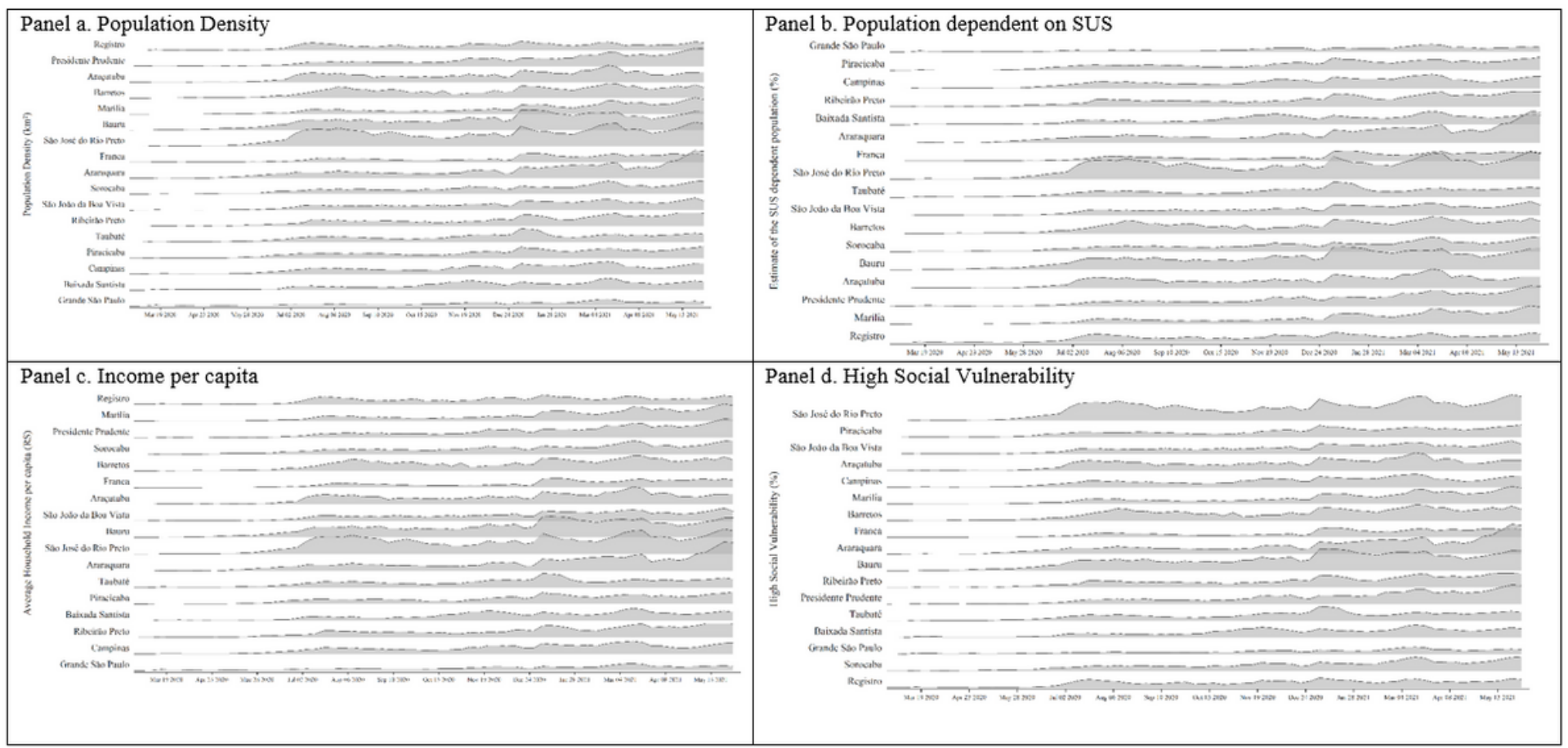

\section{Figure 4}

Variation in Testing per 100,000 and Sociodemographic Indicators across Epidemiological Weeks in the Regional Health Departments of São Paulo State (March 1, 2020 to June 5, 2021) (RHDS ranked from lowest to highest in each panel) 